\title{
Entomological aspects and the role of human behaviour in malaria transmission in a highland region of the Republic of Yemen
}

Samira M. A. Al-Eryani ${ }^{1,2^{*}}$, Louise Kelly-Hope ${ }^{3}$, Ralph E. Harbach ${ }^{4}$, Andrew G. Briscoe ${ }^{4}$, Guy Barnish¹, Ahmed Azazy ${ }^{2}$ and Philip J. McCall ${ }^{1}$

\begin{abstract}
Background: The Republic of Yemen has the highest incidence of malaria in the Arabian Peninsula, yet little is known of its vectors or transmission dynamics.

Methods: A 24-month study of the vectors and related epidemiological aspects of malaria transmission was conducted in two villages in the Taiz region in 2004-2005.

Results: Cross-sectional blood film surveys recorded an overall malaria infection rate of $15.3 \%$ (250/1638), with highest rates exceeding $30 \%$ in one village in May and December 2005. With one exception, Plasmodium malariae, all infections were P. falciparum. Seven Anopheles species were identified among 3407 anophelines collected indoors using light traps (LT) and pyrethrum knockdown catches (PKD): Anopheles arabiensis (86.9\%), An. sergentii (9\%), An. azaniae, An. dthali, An. pretoriensis, An. coustani and An. algeriensis. Sequences for the standard barcode region of the mitochondrial $\mathrm{CO}$ gene confirmed the presence of two morphological forms of An. azaniae, the typical form and a previously unrecognized form not immediately identifiable as An. azaniae. ELISA detected Plasmodium sporozoites in $0.9 \%$ of 2921 An. arabiensis (23 P. falciparum, two P. vivax) confirming this species as the primary malaria vector in Yemen. Plasmodium falciparum sporozoites were detected in An. sergentii (2/295) and a single female of An. algeriensis, incriminating both species as malaria vectors for the first time in Yemen. A vector in both wet and dry seasons, An. arabiensis was predominantly anthropophilic (human blood index $=0.86$ ) with an entomological inoculation rate of 1.58 infective bites/person/year. Anopheles sergentii fed on cattle (67.3\%) and humans (48.3; $20.7 \%$ mixed both species), but only $14.7 \%$ were found in PKDs, indicating predominantly exophilic behaviour. A GIS analysis of geographic and socio-economic parameters revealed that An. arabiensis were significantly higher $(P<0.001)$ in houses with televisions, most likely due to the popular evening habit of viewing television collectively in houses with open doors and windows.
\end{abstract}

Conclusions: The predominantly indoor human biting vectors recorded in this study could be targeted effectively with LLINs, indoor residual spraying and/or insecticide-treated window/door curtains reinforced by education to instil a perception that effective and affordable malaria prevention is achievable.

Keywords: Arabia, Plasmodium falciparum, Anopheles, Arabiensis, Sergentii, Sporozoite, EIR, Taiz, Vector, Mosquito, Surveillance

\footnotetext{
*Correspondence: samiraal@yahoo.com

${ }^{2}$ Department of Medical Parasitology, Faculty of Medicine and Health

Sciences, University of Yemen, Sana'a, Yemen

Full list of author information is available at the end of the article
} 


\section{Background}

Malaria is the most important vector-borne disease in the Republic of Yemen, where approximately $65 \%$ of the population are estimated to be at risk of infection and where the majority of malaria cases in the Arabian Peninsula occur $[1,2]$. Plasmodium falciparum is widespread and responsible for more than $95 \%$ of all cases, with the remainder caused by $P$. vivax and $P$. malariae $[1$, 3, 4]. The World Health Organization (WHO) reported that the number of confirmed cases fluctuates from year to year and precise estimates of incidence of malaria have been difficult to produce [1]. For example, in 2006, up to 900,000 cases and 9000 deaths were estimated to have occurred while 265,074 cases and 779 deaths were recorded in 2009 [5]. Yemen's climate, which varies dramatically across its diverse topography, explains, at least in part, the considerable spatial and temporal variation in malaria transmission rates. At high transmission levels, malaria can be the primary cause of paediatric hospital admissions (up to $40 \%$ in the peak malaria season), with a $0.9 \%$ mortality rate among infected individuals [6].

In 2005, a regional strategy to eliminate malaria from the Arabian Peninsula by 2020 was launched with the support of Yemen's National Malaria Control Programme (NMCP) $[2,5,7]$. That initiative highlighted the magnitude of malaria in the country and led to an increase in studies on malaria epidemiology $[3,4,6,8,9]$ and a renewed focus on vector control [7]. Malaria vector control in Yemen is based on indoor residual spraying (IRS) and long-lasting insecticidal nets (LLINs) deployed alone or in combination [7]. Malaria epidemiological stratification recognizes four strata based on altitude: stratum 1 at 0-600 m; stratum 2 at $601-1000 \mathrm{~m}$; stratum 3 at $1001-$ $2000 \mathrm{~m}$; stratum $4>2000 \mathrm{~m}$, which is considered malaria free [5].

Knowledge of the natural history of the anopheline mosquitoes in Yemen and of their potential and actual roles in transmission is sparse. Fifteen Anopheles species have been recorded in Yemen, representing the fauna of the Afrotropical, Palaearctic and Oriental regions [10, 11]. Earlier work reported that the primary vector was the Afrotropical Anopheles arabiensis, which was considered to be widespread (Toffolon, 1946 unpublished, quoted in [12-14]). Anopheles culicifacies was recorded in the coastal plains and on the island of Socotra in the Arabian Sea, and was considered the principal vector in Al-Mahra Governorate (eastern Yemen) and on Socotra $[11,15]$. Anopheles sergentii and the relatively uncommon An. fluviatilis were recorded at higher altitudes (500$1500 \mathrm{~m}$ ) and, though unproven, both were suspected of being malaria vectors [11]. Based on these reports, the current NMCP plan [7] classifies An. arabiensis and $A n$. culicifacies as vectors below altitudes of $600 \mathrm{~m}$ and $A n$. arabiensis and $A n$. sergentii at higher altitudes. Information on the distribution of Anopheles species is based on records from cross-sectional malaria surveys dating from the 1940s in published [12, 16-22] and unpublished documents $[23,24]$.

The first vector incrimination studies were conducted by Toffolon in 1944 and 1945 (see [12]), who reported finding sporozoites in the salivary glands of An. gambiae sensu lato. Plasmodium falciparum sporozoites were identified in An. arabiensis in later studies [12-14]. However, no longitudinal data exist and neither the range of anophelines present in the country nor their individual roles in malaria transmission are known. Considerable knowledge exists on the natural history, behaviour and vectorial role of the anopheline fauna in most countries that lie west of the Red Sea or east of the Persian Gulf, but extrapolation from these studies to Yemen is unlikely to be reliable, given the geographic isolation of Yemen and the unique characteristics of its arid montane habitats.

This report addresses those knowledge gaps and provides new information on the vectors of malaria, longitudinal data on entomological parameters of malaria transmission in the Taiz region and socio-cultural aspects of local communities that influence the risk of malaria. The governorate of Taiz is classed as a highly malariaendemic area and was the location for a study on clinical and epidemiological aspects of malaria $[6,25,26]$, shortly before the entomological study reported here.

\section{Methods}

\section{Study sites in Taiz governorate}

Located in southwestern Yemen, the territory within the governorate of Taiz extends from 200 to $2000 \mathrm{~m}$ above sea level (asl). The climate is sub-tropical with two wet seasons: a short season in March-May and longer heavier rains in July-September [11]. With few exceptions, natural watercourses are seasonal; either large streams that flow for 3-6 months annually or smaller streams that carry water for a few weeks in the wet seasons. Natural springs, some of which are perennial, create wetlands in places. Malaria incidence increases between November and May below $1000 \mathrm{~m}$ and between May and September above $1000 \mathrm{~m}$. Typically, transmission is unstable with outbreaks of malaria following seasonal rains [7]. To date, $P$. falciparum, $P$. vivax and $P$. malariae have been recorded $[6,11,12,22,25]$.

The geographical character of the villages in the study area is illustrated in Figs. 1, 2. The first site was at Ukaysh village $\left(13^{\circ} 39^{\prime} 12.97^{\prime \prime} \mathrm{N}, 43^{\circ} 52^{\prime} 24.31^{\prime \prime} \mathrm{E}\right.$; At Taizziyah district), 910-960 $\mathrm{m}$ asl and $20 \mathrm{~km}$ northwest of Taiz city. A large (22 ha) oasis fed by a perennial stream dominates the valley (Fig. $1 \mathrm{a}-\mathrm{c}$ ). In the wet season, overflow creates pools even when no rain falls locally, whereas in the dry 


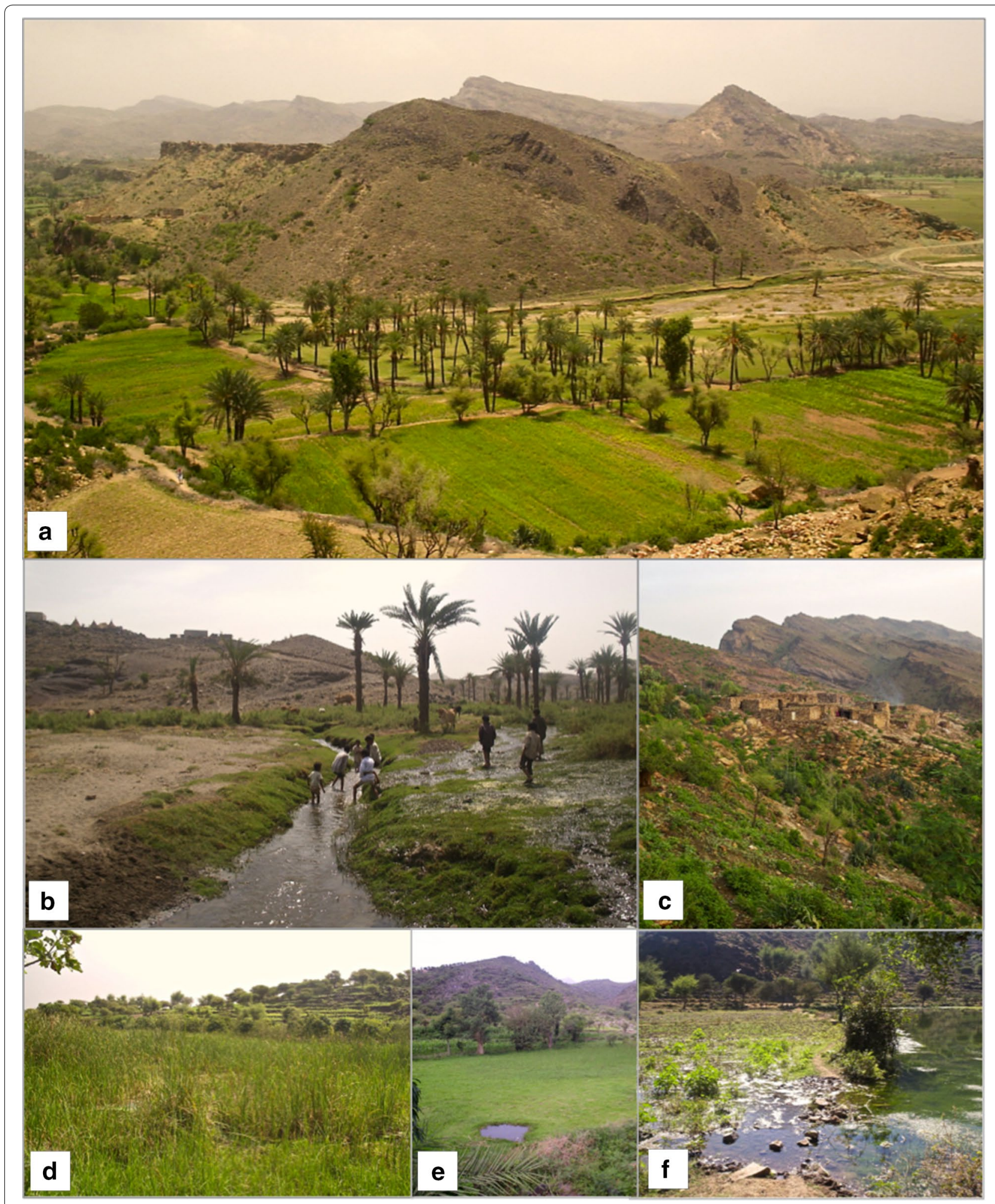

Fig. 1 The study sites in Taiz Governorate, Yemen, during the wet season in 2004 and 2005: Ukaysh, showing the large oasis (a) and its main perennial stream (b), and a cluster of houses situated on the hill overlooking the oasis (c); Al-Sa'dah showing the Wadi Mae'an' wetland (d/,e) and flooded land at Wadi Al-Ahmar (f) 


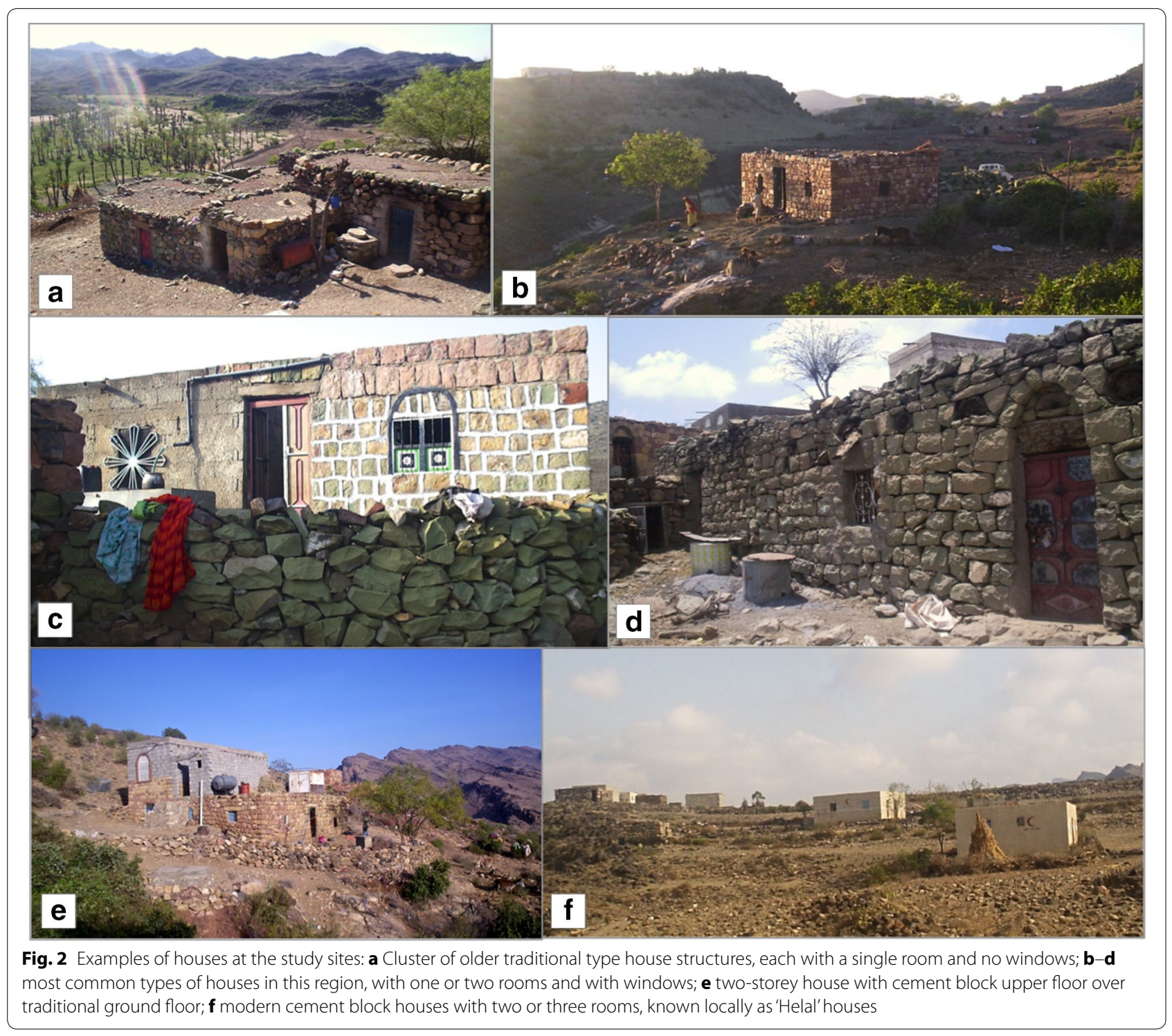

season, the villagers dig irrigation canals to divert water. The second site was Al-Sa'dah village $\left(13^{\circ} 31^{\prime} 10.49^{\prime \prime} \mathrm{N} 43^{\circ}\right.$ 56'10.79" E; Jabal Habashy district), 1340-1400 m asl and $18 \mathrm{~km}$ southwest of Taiz city, with a perennial 1.8 ha wetland area (Wadi Mae'an'; Fig. 1d, e). The nearby hamlet

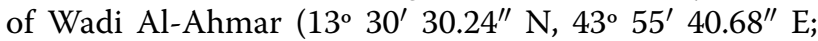
$1 \mathrm{~km}$ from Al-Sa'dah; see Fig. 1f) was sampled in November 2004-January 2005, following reports of a rise of malaria cases. Previously, Al Taiar et al. $[6,26]$ reported that malaria transmission was perennial in the Ukaysh area but limited to the wet season in Al-Sa'dah. The geographic coordinates of the aquatic habitats sampled and of all the houses at Ukaysh village where entomological, geographic and socio-economic data had been collected were recorded using a hand-held global positioning device (Magellan Meridian ${ }^{\mathrm{TM}}$ GPS, Thales Navigation).

\section{Human malaria infection survey}

Malaria infection rates in the human populations at both Ukaysh and Al-Sa'dah were carried out by microscopic examination of Giemsa-stained thick and thin blood films. Following informed consent, finger-prick blood samples were taken from all available and consenting individuals. Infection status of all blood films was examined and confirmed by the quality assurance team at the NMCP. Anti-malarial drug treatment was provided free of charge to individuals with positive blood films, 1-2 days after samples had been taken, following the WHO treatment guidelines provided by the NMCP.

Originally, two cross-sectional malaria surveys were scheduled for December 2004 and May 2005, coinciding with the dry and wet seasons respectively. However, 100 blood slides were stolen from the project vehicle in 
December 2004 and an additional survey was undertaken in December 2005 to obtain dry-season data.

\section{Mosquito collection}

The study was undertaken in 2004 and 2005, when each site was sampled at two-week intervals over 12 months: Al-Sa'dah from January 2004-2005, Ukaysh from March 2004-2005. On each sampling date, adult mosquitoes were collected from nine (the maximum number possible in 1 day) randomly selected houses by pyrethrum knockdown catch (PKD) using a local insecticide aerosol (FLEETOX ${ }^{\circledR}$; mixed pyrethroids; Arabia Felix Industries Ltd., Taiz), between 06:00 and 09:00 following WHO protocol $[27,28]$.

Light trap catches were performed in six different randomly selected houses using CDC miniature light traps (model no. 2836; Bioquip Products Inc., CA, USA). In these houses, all persons in sampled rooms were asked to sleep under an untreated bed net (provided by the investigator) and the trap was suspended from the ceiling with its light positioned at the level of the sleeper [29]. Householders switched the trap on before they slept, and off (closing the collecting bag) when they woke (typically at 06.00 ).

In June, August and December 2005 and March 2006, additional light traps were hung in animal shelters and human homes (four and two traps respectively) to investigate anopheline feeding activity on different potential hosts. Only PKD data from the longitudinal studies at both sites were used in determination of malariometric indices.

\section{Mosquito identification}

All anophelines were identified to species using the morphological key of Glick [30]. Members of the An. gambiae complex were identified using a standard rDNA-PCR method [31, 32], using a protocol described previously [33]. A number of individuals could not be identified to species with certainty using morphology-based keys [30, 34, 35]. These specimens differed from females of An. azaniae in the absence of a presector pale spot on the wing. To examine further, DNA was extracted from the abdomens of two females confirmed as An. azaniae and compared with genomic DNA from one or more legs of five unidentified anopheline adult females that originated from the same sites and that were morphologically similar to the unidentified females captured during the study. Whole genomic DNA was extracted using the Qiagen DNeasy Blood and Tissue Kit (Qiagen Ltd, Sussex, England) following the manufacturers protocols. A ca. 658 bp fragment of the standard barcode region of the mitochondrial COI gene was amplified using the primers and thermal profiles described by Cook et al. [36]. Successfully amplified PCR products were cleaned using PCR cleanup filter plates (Merck Millipore) and subsequently sequenced bidirectionally using the same primers as for amplification. Accession numbers are available on request from the authors.

\section{Blood meal analysis}

Individual abdomens of engorged female anophelines were crushed onto Whatman ${ }^{\circledR}$ filter paper (No.3; $110 \mathrm{~mm}$ diameter) and stored at $4{ }^{\circ} \mathrm{C}$ in self-sealing plastic bags containing silica gel until examined by direct enzyme-linked immunosorbent assay (ELISA) [37]. Each sample was screened for human, bovine, goat and sheep blood in four separate ELISAs. Positive results were read visually $30 \mathrm{~min}$ after adding the substrate ABTS (2,2' azino-bis 3-ethylbenzhiazoline-6-sulphonic acid) and hydrogen peroxide (Kirkegaard and Perry Labs, USA) in a 1:1 mixture ratio. A sub-sample of 100 positive specimens for each assay was re-run to confirm the results. All inconclusive or ambiguous results were re-tested once.

\section{Detection of sporozoites}

Individual mosquito heads and thoraces were stored in 1.5- $\mu \mathrm{l}$ Eppendorf tubes in self-sealing plastic bags containing silica gel, for subsequent examination for $P$. falciparum and $P$. vivax circumsporozoite protein (CSP) by ELISA. A standard CDC protocol for the Antibody Sandwich ELISA method based on previously published techniques $[38,39]$ was used. Results were read visually $30-60 \mathrm{~min}$ after adding the substrate. Positive results (visible colour in wells) were retested for confirmation.

\section{Climatic data}

Climate data were obtained from satellite images from the IRI/LDEO Climate Data Library of the International Research Institute for Climate and Society [40]. Estimated monthly precipitation $(\mathrm{mm})$, mean monthly temperature $\left({ }^{\circ} \mathrm{C}\right)$ and mean monthly specific humidity (aq) were obtained from satellite data recorded by the National Oceanic and Atmospheric Administration (NOAA) and based on daily mean readings taken $2 \mathrm{~m}$ above the ground. This data source records specific humidity rather than relative humidity. Specific humidity measures the actual water vapour content in the air (mass of water vapour for a given mass of air expressed as grams of water vapour per kilogram of air) and is not affected by air temperature, whereas relative humidity measures the percentage of actual water vapour relative to the temperature [41].

\section{House survey and knowledge, attitudes and perception (KAP) survey}

At the beginning of the study, data on house size and structure, numbers of persons sleeping there, presence 
of animals (inside/outside) the house and key possessions were recorded for all houses. Following verbal consent, information on education, mosquito prevention practices, and knowledge and perception of malaria and mosquitoes were recorded in face-to-face interviews with a senior adult member of each household, using a standard questionnaire [42] (Additional file 1).

\section{Data analyses}

Data entered in Microsoft Excel were transferred into SPSS for Windows version 16.0. The monthly means of $A n$. arabiensis were calculated by dividing the total number of PKD-collected specimens by the number of houses sampled for each month. As this was not normally distributed, values were transformed by natural log function, with a factor of one added to eliminate zero values [43]. Geometric means (GM) were calculated and $95 \%$ confidence intervals (CI) obtained based on the assumption of normal distribution. The seasonal abundance of An. arabiensis for each site was plotted using the GM and the $95 \%$ CI (upper and lower limits). Bivariate correlation was used to investigate associations between climate variables and mean monthly abundance of An. arabiensis. Analysis of variance (ANOVA) was used to compare more than two means.

ArcGIS software 9.1 (ArcInfo ${ }^{\circledR}$ Environmental Systems Research Institute Inc., ESRI, Redlands, CA, USA) was used to produce a digital map of the study site at Ukaysh. Distances between houses, An. arabiensis larval habitats (distance of each house from the nearest positive site) and other key physical features within the site were measured using ArcGIS 9.1.

For spatial analyses, mean numbers of $A n$. arabiensis per house were calculated by dividing the total by the number of sampling days. The Poisson skewed count data were transformed by taking the natural log of the mean number of adult female $A n$. arabiensis per house $(+1$ to eliminate zero values). These logged mean numbers of $A n$. arabiensis per house were explored for association with explanatory variables, including geographic, socioeconomic and demographic factors. Distances to the nearest larval habitats of $A n$. arabiensis were grouped into three categorical variables (0-100, 101-200 and $>201 \mathrm{~m}$ ) and the association between the variables and the abundance of $A n$. arabiensis were analysed using correlation/ANOVA methods. The geometric means of $A n$. arabiensis with a $95 \% \mathrm{CI}$ were obtained by antilog of the logged means with upper and lower limits.

\section{Ethical considerations}

Ethical clearance for the study "Vectorial parameters of malaria transmission in Taiz, Yemen" was granted by the Faculty of Medicine and Health Sciences,
University of Sana'a, and the Research Ethics Committee at the Liverpool School of Tropical Medicine (Ref 04.48).

\section{Results}

\section{Human malaria infections}

A total of 1724 stained blood films, were collected in December 2004, May 2005 and December 2005 at both sites, of which 285 (16.5\%) were infected. However, as 86 persons sampled (including 35 malaria positives) were not residents of either of the two study sites, they were excluded from the analysis, resulting in a malaria infection rate of $15.3 \%(250 / 1638)$ at the study sites (Table 1$)$. The highest rates of 32.4 and $31.2 \%$ were recorded at Ukaysh in May and December 2005 respectively. However, the theft of 100 blood films at this site may account, in part at least, for the lower prevalence rate of $15.3 \%$ recorded in December 2004. Infection rates were lower at Al-Sa'dah in all surveys, with the highest rate, $5.6 \%$, recorded in December 2004.

Plasmodium falciparum comprised $99.6 \%$ ( $\mathrm{n}=249 / 250$ ) of all positive slides. Plasmodium malariae was detected in one blood film at Ukaysh (Table 2). Plasmodium vivax was not detected. During routine surveys in Ukaysh, an additional 214 blood films were examined in response to requests by villagers, of which $45.7 \%$ $(\mathrm{n}=16 / 35), 34.4 \%(\mathrm{n}=32 / 93)$ and $43.0 \%(\mathrm{n}=37 / 86)$ were malaria positive, in June 2005, August 2005 and March 2006 respectively.

Prior to entomological sampling in Wadi Al-Ahmar of Al-Sa'dah, a malaria survey was carried out in November 2004. A total of 200 blood films were examined from this site, of which 29 were positive for P. falciparum (14.5\%).

Identification and relative abundance of Anopheles species A total of 3407 female anophelines were captured in light trap and pyrethrum knockdown (PKD) collections at all locations (houses and animal shelters) throughout the study (Table 2).

A sub-sample of 335 An. gambiae s.l. was examined using the standard intergenic rDNA-based PCR method. Of these, 317 produced a PCR band ( $315 \mathrm{bp})$, and all were An. arabiensis.

Two female anophelines were unidentifiable morphologically. However, COI sequences obtained for five morphologically similar females collected subsequent to the surveys were subjected to an unrestricted nucleotide BLAST search for comparison with sequences available in GenBank [44]. The COI sequence obtained from these specimens shared greatest similarity with An. funestus isolates DQ287358, DQ287358 (93 \% identity score), DQ287358, DQ287358 and DQ287358 (94 \% identity score). When the sequences were compared with those 
Table 1 Malaria infection rates during cross-sectional surveys of residents at Ukaysh and Al-Sa'dah, Taiz governorate, Yemen in 2004 and 2005

\begin{tabular}{|c|c|c|c|c|c|}
\hline Date & No. examined & No. malaria positive & P. falciparum & P. malariae & $\begin{array}{l}\text { Malaria } \\
\text { preva- } \\
\text { lence } \\
(\%)\end{array}$ \\
\hline \multicolumn{6}{|l|}{ Ukaysh } \\
\hline \multicolumn{6}{|l|}{2004} \\
\hline December & 216 & 33 & 32 & 1 & 15.3 \\
\hline \multicolumn{6}{|l|}{2005} \\
\hline May & 306 & 99 & 99 & 0 & 32.4 \\
\hline December & 276 & 86 & 86 & 0 & 31.2 \\
\hline \multicolumn{6}{|l|}{ Al-Sa'dah } \\
\hline \multicolumn{6}{|l|}{2004} \\
\hline December & 319 & 18 & 18 & 0 & 5.6 \\
\hline \multicolumn{6}{|l|}{2005} \\
\hline May & 356 & 13 & 13 & 0 & 3.7 \\
\hline December & 165 & 1 & 1 & 0 & 0.6 \\
\hline Total & 1638 & 250 & 249 & 1 & 15.26 \\
\hline
\end{tabular}

Infections were detected by microscope examination of Giemsa-stained blood films

Table 2 Total numbers of adult female anopheline mosquitoes collected in all sites during the study in 2004-2005, using pyrethrum knockdown catches (PKD) (from one room in each sampled house) and light traps (in human and animal shelters)

\begin{tabular}{|c|c|c|c|}
\hline Anopheles species & PKD (\%) & Light traps (\%) & Total (\%) \\
\hline An. arabiensis & $1879(96.4)$ & $1082(74.3)$ & $2961(86.9)$ \\
\hline An. sergentii & $45(2.3)$ & $261(17.9)$ & $306(9.0)$ \\
\hline An. azaniae (typical) & $9(0.5)$ & $45(3.1)$ & $54(1.6)$ \\
\hline An. azaniae (atypical) & 0 & $2(0.1)$ & $2(0.1)$ \\
\hline An. dthali & $13(0.7)$ & $22(1.5)$ & $35(1.0)$ \\
\hline An. pretoriensis & 0 & $30(2.1)$ & $30(0.9)$ \\
\hline An. coustani & $2(0.1)$ & $14(1.0)$ & $16(0.5)$ \\
\hline An. algeriensis ${ }^{\mathrm{a}}$ & $2(0.1)$ & $1(0.1)$ & $3(0.1)$ \\
\hline Total & 1950 & 1457 & 3407 \\
\hline
\end{tabular}

A total of 736 PKDs in 159 houses and 330 light-trap collections in 109 households were carried out

a The first record of An. algeriensis in Yemen

obtained from two specimens of $A n$. azaniae, four were found to share $98-100 \%$ identity and one differed by $7 \%$. Hence it was concluded that the two uncertain females captured during the study were atypical specimens of An. azaniae (Table 3).

Seven Anopheles species were recorded. Anopheles arabiensis was the most abundant species (86.9\%) in both PKD (96.4 \%; 1879/1950) and light-trap collections (74.3\%; 1082/1457). In contrast, more An. sergentii, the second most abundant species, were collected in light traps (85.3 \%) than PKDs (14.7 \%). Light trap catches also detected the presence of An. coustani and An. pretoriensis (Table 3).
Anopheles arabiensis and An. sergentii were found at all sampling sites, though numbers were higher in Ukaysh where almost $90 \%(3065 / 3407)$ of the total catch was taken and all but one species, An. coustani, were recorded. The remaining mosquitoes were captured at Al-Sa'dah (335 individuals identified as An. arabiensis, An. sergentii, An. pretoriensis and An. coustani) and at AlTayyar hamlet adjacent to Ukaysh (seven mosquitoes: $A n$. arabiensis, An. sergentii, An. dthali and An. algeriensis).

\section{Seasonal variation in abundance of Anopheles species}

At Ukaysh, An. arabiensis was the predominant species and was recorded on all sampling dates, with sample sizes 
Table 3 Identification of Anopheles adults based on comparison of their COI mtDNA sequence

\begin{tabular}{|c|c|c|}
\hline Specimen & Locality & Species \\
\hline ㅇ 40-55 & Ukaysh & An. azaniae (typical) ${ }^{a}$ \\
\hline ㅇ 43-59 & Ukaysh & An. azaniae (typical) ${ }^{\mathrm{a}}$ \\
\hline 우 29-52 & Ukaysh & $\begin{array}{l}\text { An. azaniae (atypi- } \\
\text { cal) }\end{array}$ \\
\hline ๙ Ukaysh 2005 & Ukaysh & $\begin{array}{l}\text { An. azaniae (atypi- } \\
\text { cal) }\end{array}$ \\
\hline o $33-52$ & Ukaysh & $\begin{array}{l}\text { An. azaniae (atypi- } \\
\text { cal) }\end{array}$ \\
\hline 우 3-59 & Ukaysh & $\begin{array}{l}\text { An. azaniae (atypi- } \\
\text { cal) }\end{array}$ \\
\hline o Al Sadah tank 2004 & Al Sa'dah & An. species? \\
\hline
\end{tabular}

See the "Discussion" section for morphological distinctions

a Morphologically confirmed females used for comparison with the other five specimens

ranging from five (January 2005) to 495 (March 2005) individuals. The largest sample size for all other species was six, for An. dthali in December 2004.

The abundance of $A n$. arabiensis and associated satellite climatic variables (estimated precipitation, mean temperature and specific humidity) for January 2004March 2005 are shown in Fig. 3. Monthly collections were significantly different $(P<0.001)$ but there was no correlation between abundance and mean monthly temperature $(r=0.228 ; P=0.453)$, specific humidity $(r=0.021 ; P=946)$ or estimated precipitation $(r=0.085$; $P=0.783)$. The National Malaria Control Programme carried out larviciding in August 2004 when all known larval habitats of Anopheles species at Ukaysh were treated; mosquito abundance was dramatically lower on the survey immediately after (Fig. 3).

At Al-Sa'dah, PKD samples collected between November 2004 and January 2005 comprised An. arabiensis (85.2 \%, 127/149) and An. sergentii (13.4 \%, 20/149). The largest PKD sample was recorded in November 2004 when 45 female An. arabiensis were collected in a single room.

\section{Identification of blood meal sources in Anopheles females}

A total of 1233 blood-fed mosquitoes collected by all methods on all dates were screened using ELISA to identify blood meal sources (Table 4). Humans were the most common host for all mosquitoes (65.4\%), with cattle or a mixture of cattle and human blood accounting for $28 \%$ of the blood meals. Goat blood was identified in only $2.4 \%$ of blood meals and no mosquitoes had fed on sheep. Blood from more than one host was identified in 183 mosquitoes (14.8\%). Anopheles arabiensis had fed predominantly on humans $(82.8 \%, 946 / 1143)$, whereas $67.2 \%(39 / 58)$ and $48.3 \%(28 / 58)$ of An. sergentii had fed on cattle and humans, respectively.
Of the blood meals identified from the Ukaysh longitudinal PKD data alone, 760/767 were from An. arabiensis and $86.0 \%$ of those were of human origin $(\mathrm{n}=554$ from humans, 101 mixed human and bovine; 72 bovine, seven goat and 26 from unidentified hosts). Hence, the human blood index (HBI) for An. arabiensis was calculated as 0.862 [45]. Of 41 anopheline females analysed from AlSa'dah, the majority $(35 / 41,85.0 \%)$ had fed on humans: An. arabiensis $(95.0 \%, 19 / 20)$, An. sergentii $(82.4 \%$, 14/17), An. coustani (1/2), An. pretoriensis (1/2).

\section{Plasmodium sporozoite rates}

A total of 3343 anopheline mosquitoes were screened for the presence of sporozoites, and infections were detected in $28(0.8 \%)$ females of three species: 25 An. arabiensis (P. falciparum and P. vivax), two An. sergentii (P. falciparum) and one An. algeriensis (P. falciparum) (Table 5a).

Of the 1617 anopheline females from the 12-month longitudinal study at Ukaysh (i.e. PKD data only; Table 5b), 18 An. arabiensis were infected with P. falciparum and one with $P$. vivax ( $P v 247)$, yielding a sporozoite rate of $1.2 \%(\mathrm{n}=19)$. The infected An. arabiensis were found in April (2/129), June (8/138) and December (1/21) of 2004, and February (2/331) and March (6/487) of 2005. The monthly sporozoite rate ranged from 0 to a high of $5.8 \%$ in June.

At Al-Sa'dah, only An. sergentii was infected, with a sporozoite rate of $1.7 \%(\mathrm{n}=2 / 118)$. The infected females were found in light trap collections in November 2004 (1/92 examined) and by PKD in January $2005(1 / 20)$. Based on the longitudinal PKD survey, the sporozoite rate in An. sergentii at Al-Sa'dah was 5 \% (Table 5c).

\section{Entomological inoculation rate (EIR)}

The EIR index, a measure of the number of infective bites per person per unit time, was calculated from the human biting rate $[=0.36$; the mean number of human bloodfed mosquitoes (PKD data from the longitudinal survey only $=6.7$ ), divided by the mean number of house occupants $(=16)$ and multiplied by the human blood index $(=0.86)]$ multiplied by the sporozoite rate $(=1.2 \%)$. The EIR for Ukaysh was calculated as 1.58 per annum. Thus, individuals in Ukaysh received 1.58 infective bites/person/year from An. arabiensis alone.

The EIR in Al-Sa'dah was lower, with transmission detected only after the rainy season, and an average of 0.003 infective bites/person/month or 0.04 infective bites/person/year.

\section{Demographic and socio-economic survey at Ukaysh}

The total population of Ukaysh was 407 (203 males and 204 females). The median age for the female population was 13 years (range $0-80$ years) and 15 for males (range 
a

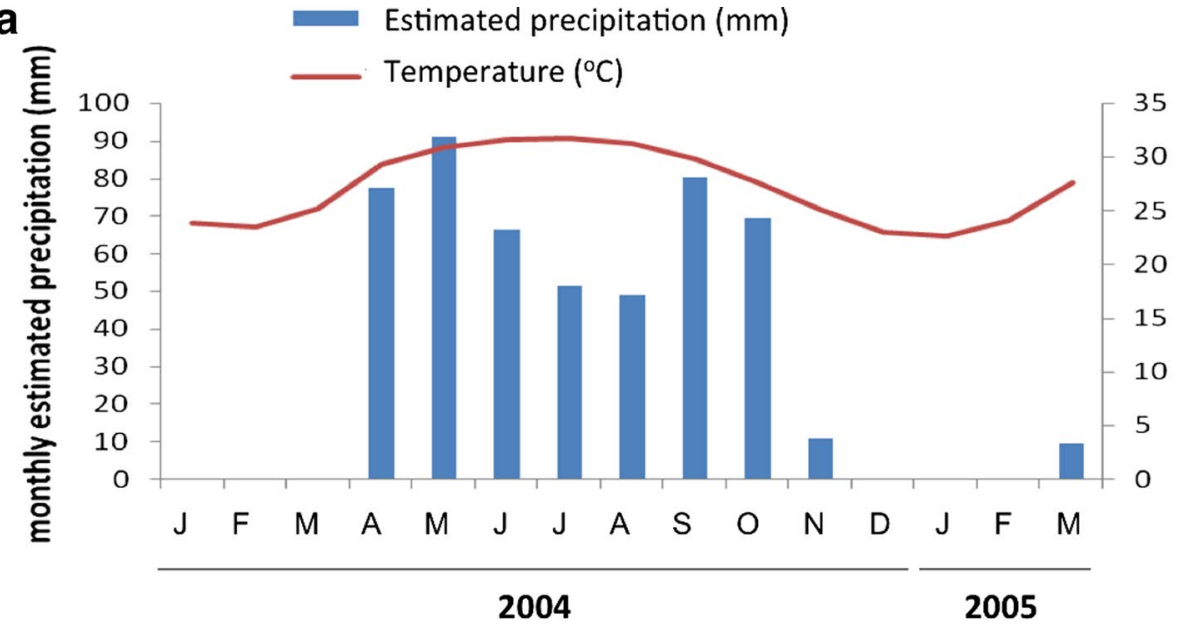

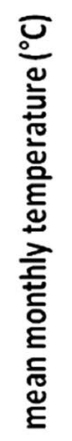

b

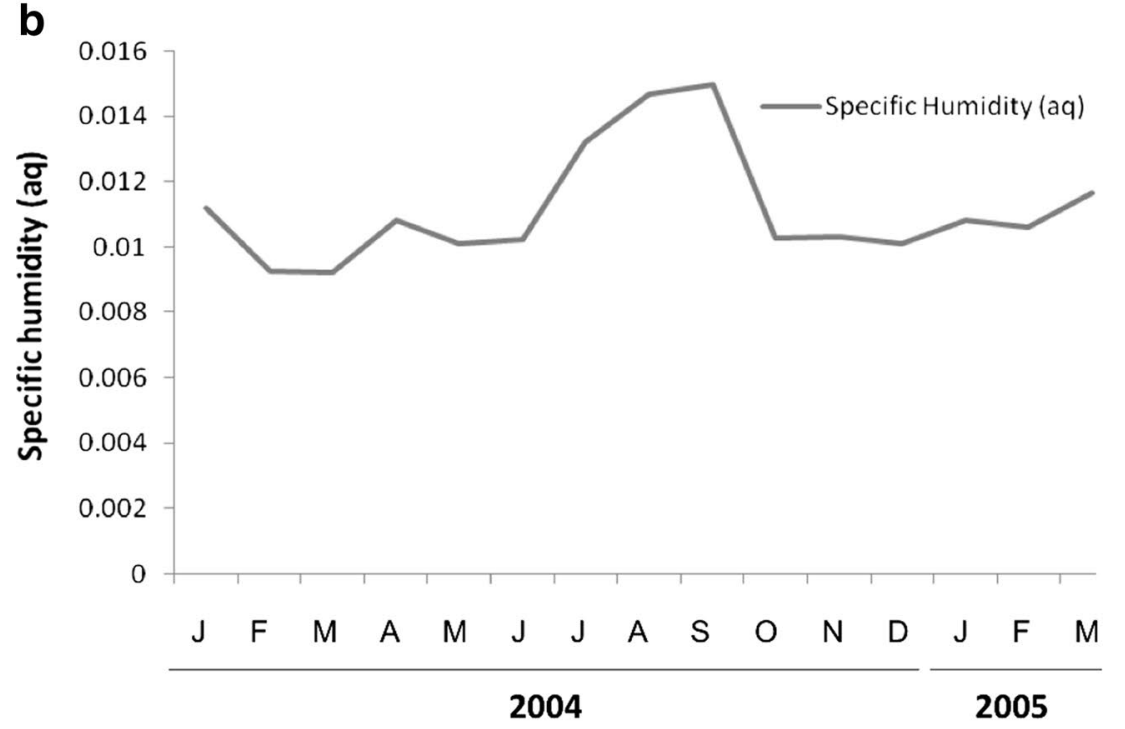

C

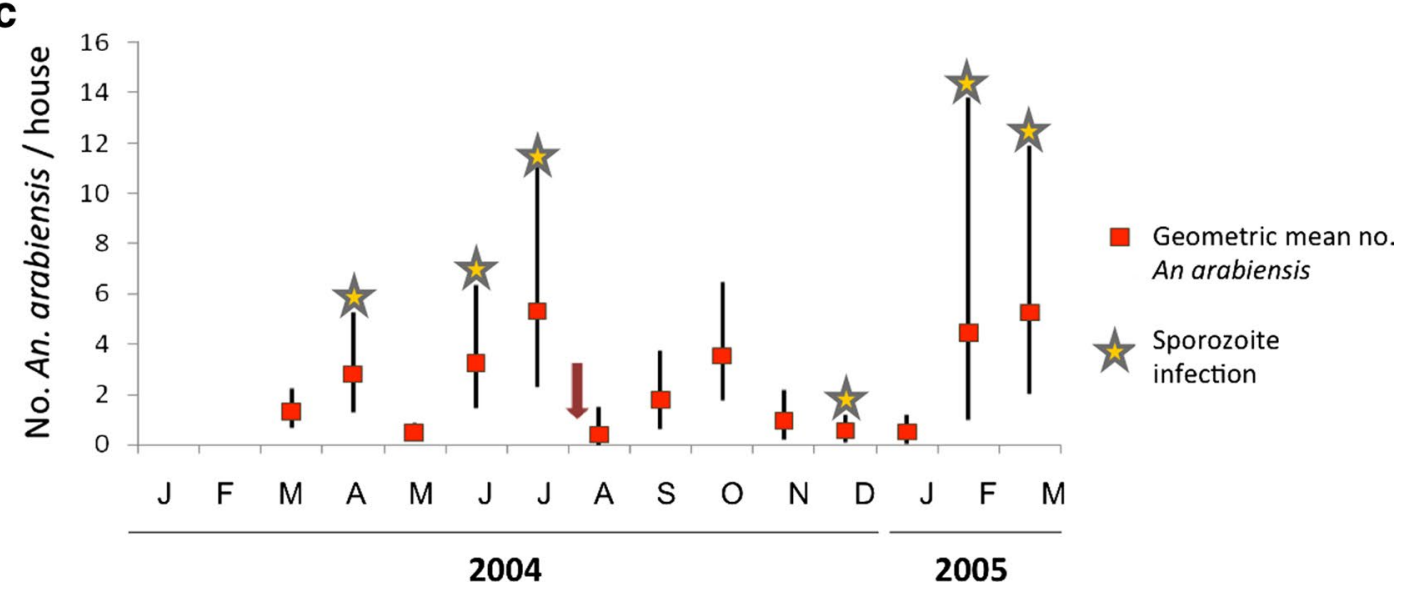

Fig. 3 Estimated precipitation and mean temperature data (a) and specific humidity (b) at Ukaysh, Taiz governorate, Yemen from January 2004 to March 2005 (http://iridl.Ideo.columbia.edu); c Monthly abundance of Anopheles arabiensis (geometric mean number of mosquitoes per house collected by pyrethroid knockdown catch [PKD], with 95 \% confidence interval) at Ukaysh (March 2004-March 2005). The red arrow indicates the date (1 Aug 2004) when The National Malaria Control Programme carried out larviciding at all the known larval habitats of Anopheles at this site 


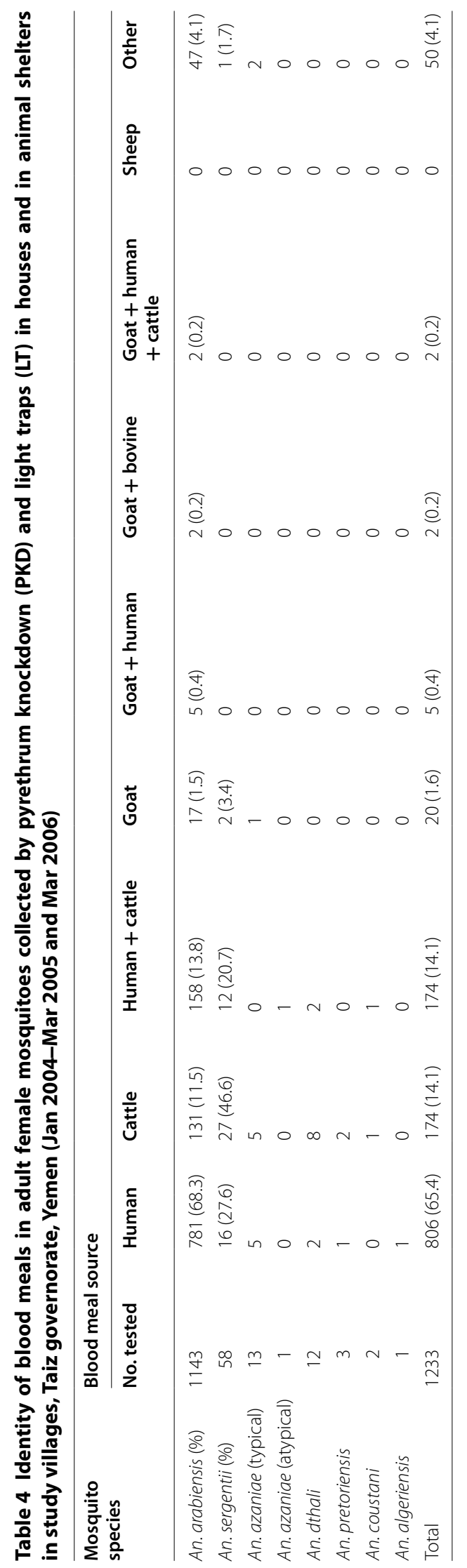


Table 5 The total numbers of Anopheles mosquitoes examined and sporozoite infection rates in females collected by both pyrethrum knockdown catches (PKD) or light traps (LT) between January 2004 and March 2005 at all sites, and as collected by PKD sampling only at Ukaysh and Al Sadah

\begin{tabular}{|c|c|c|c|c|}
\hline $\begin{array}{l}\text { Anopheles } \\
\text { species }\end{array}$ & $\begin{array}{l}\text { No. of females } \\
\text { examined }\end{array}$ & P. falciparum & P. vivax & $\begin{array}{l}\text { Sporozoite } \\
\text { rate }\end{array}$ \\
\hline \multicolumn{5}{|c|}{ A. All collection sites, on all dates, PKD and LT catches } \\
\hline An. arabiensis & 2921 & 23 & 2 & 0.9 \\
\hline An. sergentii & 295 & 2 & 0 & 0.7 \\
\hline An. azaniae & 49 & 0 & 0 & 0 \\
\hline An. dthali & 29 & 0 & 0 & 0 \\
\hline An. pretoriensis & 30 & 0 & 0 & 0 \\
\hline An. coustani & 16 & 0 & 0 & 0 \\
\hline An. algeriensis & 2 & 1 & 0 & 50.0 \\
\hline Anopheles sp. & 1 & 0 & 0 & 0 \\
\hline Total & 3343 & 26 & 2 & 0.8 \\
\hline \multicolumn{5}{|c|}{ B. Ukaysh_Longitudinal study (Mar 2004-Mar 2005) PKD data } \\
\hline An. arabiensis & 1590 & 18 & 1 & 1.2 \\
\hline An. sergentii & 15 & 0 & 0 & 0 \\
\hline An. azaniae & 4 & 0 & 0 & 0 \\
\hline An. dthali & 7 & 0 & 0 & 0 \\
\hline An. algeriensis & 1 & 0 & 0 & 0 \\
\hline Total & 1617 & 18 & 1 & 1.2 \\
\hline \multicolumn{5}{|c|}{ C. Al-Sa'dah-Longitudinal study (Jan 2004-Jan 2005) PKD data } \\
\hline An. arabiensis & 125 & 0 & 0 & 0 \\
\hline An. sergentii & 20 & 1 & 0 & 5 \\
\hline An. coustani & 2 & 0 & 0 & 0 \\
\hline Total & 147 & 1 & 0 & 0.7 \\
\hline
\end{tabular}

1-80 years); $19.7 \%$ of the total population was younger than 5 years old. Ukaysh had a total of 62 houses of four types: older traditional houses with one room and no windows, typically clustered together (Figs. 1c, 2a); the most common larger traditional houses with one or two rooms and with windows (Fig. 2b-d) or two-storey houses with cement block upper floors over traditional ground floor (Fig. 2e); modern cement block houses with two or three rooms and windows, known locally as 'Helal' houses (Fig. 2f). Only nine houses (eight typical and the top rooms of one two-storey house) had window nets, most of which were damaged with holes. Typically, rooms were sealed with mud, with an earth roof and floor and a 'lath and plaster' ceiling; however, 23 houses (37\%) had timber ceilings.

Over $90 \%$ (59/62) of the houses had associated animals (cattle, goats or sheep). Most houses had separate animal shelters attached to or very close to the house, but animals, especially cattle, were kept within $31.0 \%$ $(18 / 59)$ of the houses. The majority of the heads of households at Ukaysh were illiterate $(86.7 \%)$. Most of the respondents perceived malaria as a problem (96.7 \%) and mosquitoes as the cause $(71.7 \%)$. Fever and vomiting were the most common (over $90 \%$ ) symptoms and signs associated with malaria, though convulsions $(23.3 \%)$ in children and coma (3.3\%) were also mentioned. The majority $(96.7 \%)$ recognized that the oasis surrounding the village was the source of mosquitoes and most $(86.7 \%)$ reported that mosquitoes bit at night all year round. The most popular local method of protection was to burn cow dung or shrubs (91.7\%), usually at the house entrance during the early evenings and prior to sleep. The second choice of protection mentioned was burning insecticide coils (30.0\%) inside the houses before sleeping. Only $18.3 \%$ reported using insecticide aerosols.

\section{Risk factors for An. arabiensis infestation in houses at Ukaysh}

Of the 62 houses in Ukaysh, 59 were sampled by PKD for adult mosquitoes during March 2004-March 2005. Anopheles arabiensis were collected from $79.7 \%$ of the houses ( $n=1602$ mosquitoes), four of which (6.8\%) yielded $56.7 \%(909 / 1602)$ of the total. To investigate which parameters might have influenced mosquito entry and therefore malaria risk, associations between $A n$. arabiensis infestation rates and a range of domestic, geographic and socio-economic parameters were explored.

The houses in Ukaysh were clustered in seven hamlets and there was a significant difference $(P=0.001$; ANOVA) in the numbers of $A n$. arabiensis caught in each hamlet, with higher numbers caught in the two 'inner hamlets' (Fig. 4a). The number of An. arabiensis was also positively correlated with the number of human occupants in the house (Pearson's Bivariate correlation; $r=0.361 ; P=0.005$ ) (Fig. 4b). Anopheles arabiensis infestations differed significantly between different house types, and the number of females was significantly higher $(P<0.001)$ in houses with televisions $(\mathrm{n}=18)(5.7 ; 95 \%$ CI 2.8-10.8) than those without $(\mathrm{n}=41)(1.4 ; 95 \% \mathrm{CI}$ 0.8-2.1) (Figs. 4c, 5).

The houses with the greatest number of $A n$. arabiensis, i.e. in the two 'inner hamlets', were located approximately $200 \mathrm{~m}$ and more from the nearest larval habitats of $A n$. arabiensis (mainly simple irrigation canals and ground pools). Houses located closer to the positive habitats (at the perennial stream), at $0-100 \mathrm{~m}$ and less than $200 \mathrm{~m}$, had lower numbers of $A n$. arabiensis.

Infestation rates were not significantly different between homes that did or did not house animals overnight $(P=0.674)$. There were no differences in numbers of mosquitoes found in houses with different internal construction (i.e. houses with 'lath and plaster' or 'wood/timber' ceilings; $P=0.346$ ). The numbers of 


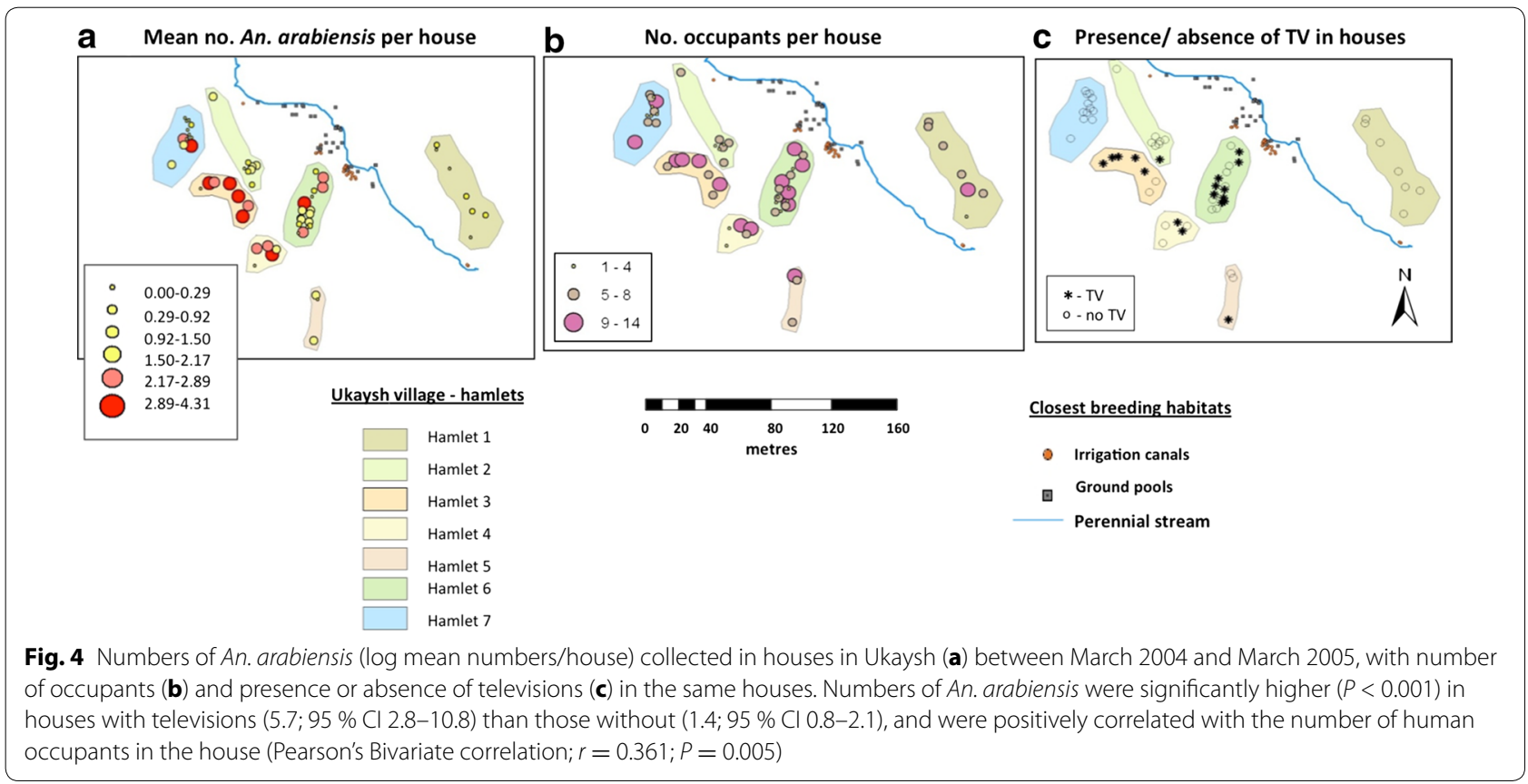

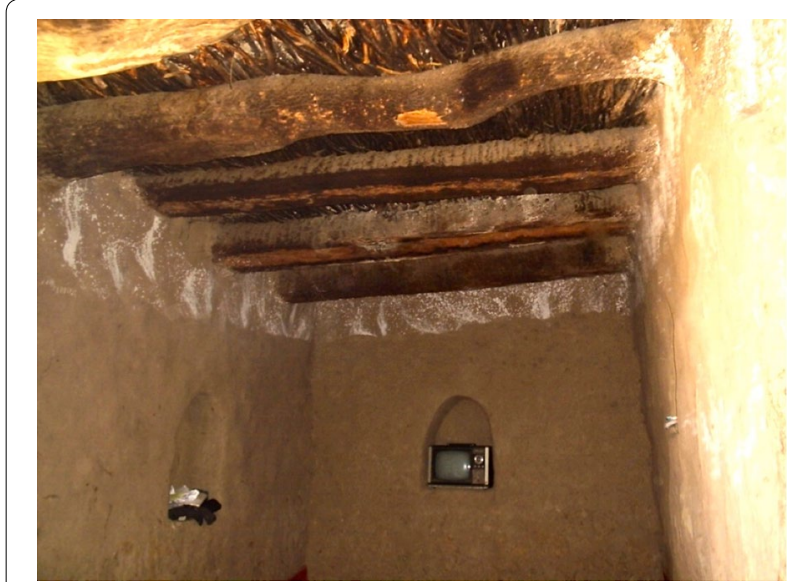

Fig. 5 A television set within a house in Ukaysh, Taiz governorate, Yemen. Typically, up to 18 people would gather within this room every night between 19:00 and 23:00 with windows and doors left open for ventilation

An. arabiensis resting inside the houses was not significantly different in houses with or without window netting $(p=0.641)$, though it was noted that the window nets were usually damaged with holes and therefore would not have prevented mosquitoes from entering. Vector infestation rates were not influenced by the education level of the head of the household (i.e. the respondent in KAP survey; $P=0.881$ ) or the socio-economic index (number of items owned) by the household $(P=0.117)$.
Finally, the use of mosquito repellents by the locals (e.g. burning dung or vegetation to produce a repellent smoke), whether used alone or in combination with mosquito coils or domestic insecticide aerosols, did not affect mosquito entry and there were no significant differences between these groups and those houses that did not use any form of repellent $(P=0.143)$.

\section{Discussion}

This study is the first comprehensive longitudinal study of malaria transmission conducted in Yemen. Adult females of seven anopheline species (An. arabiensis, An. sergentii, An. dthali, An. azaniae, An. pretoriensis, An. coustani and An. algeriensis) were found within houses in the governorate of Taiz, one of the principal malaria-endemic areas in Yemen. Anopheles arabiensis and An. sergentii were infected with human plasmodial parasites and occurred in sufficiently high numbers to conclude that they are the main malaria vectors. Malaria sporozoites were found also in a single An. algeriensis female, but the scarcity of this species suggests it is unlikely to be of importance in transmission, at least in the study area.

Anopheles arabiensis was by far the most abundant mosquito species, comprising $86.9 \%(n=2961 / 3407)$ of the total adult female anophelines present in both PKD and light-trap collections. This was the only member of the An. gambiae complex found in the study area, confirming previous studies by Townson et al. [46]; from a museum specimen] and by Al-Sheikh [14]. The latter study identified mosquitoes from the Tihama area 
bordering Saudi Arabia, where this species was also the most prevalent anopheline.

High numbers of An. arabiensis dominated (96.4\%) the PKD collections, a method that selectively collects endophilic species. Clearly it is the dominant anthropophilic species in the study area. Although outdoor collections were not made, the number of anopheline females captured indoors clearly demonstrates a strong endophilic behaviour of An. arabiensis in this region, as in Africa [47-50] and confirms previous records from the Taiz [24] and Tihama areas of Yemen [13, 14]. However, additional exophagic or exophilic behaviour cannot be excluded since the collection methods used would not have captured such mosquitoes. Consequently, while a high degree of contact took place between An. arabiensis and humans indoors, it cannot be concluded that An. arabiensis was solely endophagic and endophilic in this region, and further studies are needed. Anopheles arabiensis exhibits exophilic behaviour in many regions of Africa [51-56], and both endophily and exophily may occur in the same population [50,57-60], either as a 'natural' behaviour or as a selected response to indoor residual spraying [61].

The HBI of An. arabiensis was $86.2 \%$ (all blood meals containing human blood; $72.9 \%$ for human blood alone). The high HBI recorded here corresponds with those recorded in many studies in Africa. Various studies have recorded HBI levels up to $86 \%$ (north eastern Tanzania and Malawi [49, 56]), $83.4 \%$ (eastern Sudan [48]) and $82 \%$ (central Sudan [62]) In Africa there can be marked variation in $\mathrm{HBI}$ in different areas. A very low HBI $(0.23)$ was found in Kenya, where large numbers of cattle were present [58], whereas in another study near Kisumu in western Kenya, none of the An. arabiensis screened had fed on humans, although $0.6 \%$ were $P$. falciparum sporozoite-positive [52], implying predominantly zoophagic behaviour. Conversely, in the Gambela area of Ethiopia, where there were no cattle or other livestock, An. arabiensis fed entirely on humans [63]. High HBI values of 0.99 were found in Mozambique [64], 0.923 in southern Zambia [65] and 0.911 on the Kenyan coast [66].

While the proportion of negatives or unidentified blood meals $(4.1 \%)$ recorded in this study might be due to feeding on non-human hosts, the likelihood that many blood meals had degraded before processing is high. The very low humidity in the study sites meant that approximately $4 \%$ of the captured mosquitoes had dried before or during storage (or indeed, some of the blood meals may also have degraded during transfer from the field to the laboratory), a phenomenon that has been recorded in other studies [50,67].

Anopheles arabiensis females were present in the study area throughout the collection period, although fluctuations in abundance occurred at each study site. At Ukaysh, where this species was most common, there was a significant difference between the monthly collections $(P<0.001)$. Two peaks were observed: one in the hot summer (June-July) and another in the warm spring (February-March) (Fig. 3c). There was no correlation between the monthly abundance of An. arabiensis and climate. Previously, Al-Maktari and Bassiouny [13] recorded peaks of An. arabiensis in the months of March, July and August in Zabid district, Al Hudaydah. The increase in densities of An. arabiensis during February and March in Ukaysh most likely resulted from a combination of warmer temperatures during these months and the seasonal construction of many irrigation canals for crops from the main stream in the village, which created more larval habitats. Such increases in numbers of An. arabiensis have been associated with irrigation canals in Tanzania and Kenya [52, 56, 68].

Although An. sergentii was the second most abundant Anopheles species encountered in this study, it comprised only $9.0 \%(\mathrm{n}=306 / 3,407)$ of all anophelines collected. Anopheles sergentii has been found in most regions of Yemen except coastal areas $[11,13,14,18,19$, 23, 24]. In this study, over $85 \%$ of An. sergentii were collected in light traps $(n=261 / 306)$ rather than by PKD at both study sites (39 and $6 \%$ at Al Sa'dah and Ukaysh respectively). The presence of $A n$. sergentii in light-trap collections and comparatively low numbers in PKD collections indicate the relatively uncommon combination of endophagic and exophilic behaviour. This is surprising as, given the arid nature of the region, endophily might be expected. Anopheles sergentii was reported to seek resting places in "caves and fissures" in hills in Jordan [69] and clearly its resting sites should be investigated further. Light traps have been effective for collecting exophilic An. sergentii at low densities in southern Iran [70].

The HBI of An. sergentii was 48.3 \% (from 58 specimens collected by PKD and light traps during the entire study), with a higher proportion of bovine blood meals (46.6\%) than An. arabiensis (Table 4). Anopheles sergentii is known to be zoophilic $[67,71,72]$.

Anopheles azaniae is of interest here as the atypical females (Table 3) were not readily identifiable using available identification keys [30, 34, 35]. A single specimen analysed had a mixed human/bovine blood meal and therefore must be considered anthropophilic and a potential malaria vector. Further investigation of $A n$. azaniae is needed to determine the relative abundance of the two forms, their distribution and vectorial status, particularly since larvae of the atypical form were found in water tanks adjacent to houses.

The atypical form of An. azaniae differed from the typical form in lacking a presector pale spot on the wing. 
Other distinctions included the absence of small pale spots at the bases of veins $\mathrm{R}_{4+5}, \mathrm{M}_{1+2}$ and $\mathrm{M}_{3+4}$ (adjacent to the mediocubital crossvein, morphological terminology of Harbach and Knight [73], which are present in An. azaniae, and the presence of a weakly developed presector pale spot on the costa of two of four females. Unlike the atypical specimens of An. azaniae, which have three costal pale spots (sector, subcostal and apical) that separate four dark areas, the wings of the specimen with a $7 \%$ difference in COI sequence had only two costal pale spots (subcostal and preapical) separating three dark areas, which led to the couplet that distinguishes between subgenera Anopheles and Cellia in the key of Glick [30]. The specimen also differed from the typical and atypical forms of An. azaniae in having no pale spots on the wings other than the sector pale (on the costa only) and the subcostal pale (on the costa and radius-one), and also in being a slightly larger and paler mosquito. These significant differences suggest that the specimen is likely to be a member of a species new to science.

Sporozoites of $P$. falciparum and $P$. vivax were identified in 28 mosquitoes of three anopheline species. Plasmodium falciparum was the predominant species $(92.9 \%, 26 / 28)$. Plasmodium vivax was only detected in two An. arabiensis females (Table 5a): one with Pv210 and the other with Pv247. Anopheles arabiensis was the primary vector with an overall CS rate of $0.9 \%(25 / 2921)$, of which 23 were $P$. falciparum and two were $P$. vivax. A higher CS rate of $1.2 \%(19 / 1590)$, of which 18 were $P$. falciparum and one was $P$. vivax, was calculated from the PKD collections carried out at Ukaysh during March 2004-March 2005. Previously in the Tihama area, slightly lower sporozoite rates of $0.65 \%$ [14] by PCR and $0.7 \%$ by salivary gland dissection [13] were recorded. This rate is lower than in Africa where sporozoite rates in An. arabiensis can range from $2 \%[49,74,75]$ to over $7 \%$ [76]. However, sporozoite rates similar to that detected in the present study have been recorded for this species in Eritrea (0.54-1.3 \%; [77]), Ahero in western Kenya (1.1\%; [52]) and in eastern Sudan (1.4 \%; [48]). Indeed, a very low sporozoite rate of $0.38 \%$ was found in the semiurban region of Ifakara town, Tanzania [78]. These variations may be due to different feeding behaviour of $A n$. arabiensis in the different regions. Sporozoite rates are lower when the vector is more zoophilic and when other more efficient vectors are also present [79]. Moreover, ELISA and PCR have been shown to be more sensitive than salivary gland dissection [80].

Anopheles sergentii had a CS rate of $0.7 \%(2 / 295)$. Until now, this species was only suspected to be a secondary vector in Yemen based on high densities reported during malaria outbreaks. In the Asir region of neighbouring Saudi Arabia, it is a known vector of malaria [81]. The sporozoite rate found in An. sergentii in this study is similar to that found in Egypt for P. falciparum (1.35 \%; [82]) and $P$. vivax (1.2\%; [83]).

It is interesting that one of three females of An. algeriensis collected in the present study was infected with P. falciparum sporozoites. This is the first record of this species in Yemen, which is at the south-eastern edge of its known range that includes the Middle East, northern Africa and Europe from the Mediterranean to Ireland [84]. It was recorded as a potential vector during an outbreak of malaria in Libya [85]. In a recent report on vector control in the Middle Eastern Region during the 1991 war with Iraq, An. algeriensis was regarded as a potential vector in the Arabian Peninsula and southern Iraq [86].

The entomological inoculation rate (EIR) was calculated only from the PKD collections conducted during the longitudinal study. In Ukaysh, the villagers received 1.58 infective bites/person/year from An. arabiensis, the only vector at this site. Higher EIR values typically are recorded in malaria-endemic African countries where this species and others of the An. gambiae complex and $A n$. funestus are vectors, although great variation can occur. Hay et al. [87] reviewed EIR values in the African continent where a mean annual EIR of 121 infective bites per person per year was calculated, but with a range of 0-884. Rural regions have a mean EIR of 146 (0-884), areas with irrigated rice surroundings had a lower mean of 99 (0-601) and those in urban areas showed the least exposure with a mean of $14(0-43)$ [87]. Lower EIRs were found in rural parts of the Gambia, ranging from $0.44-11.15$ [88].

Inoculation rates can also vary annually. In southern Zambia, following prolonged drought in 2004-2005, Kent et al. [65] recorded zero transmission but the following year, the EIR was 1.6 and 18.3. In different ecological zones in Eritrea, EIRs for An. arabiensis between 0 and 70 infective bites/person/year have been recorded [89]. The method of estimating EIRs and the heterogeneity of transmission within each site have been shown to yield geographically significant differences in the intensity of malaria transmission across countries of sub-Saharan Africa [90].

With the use of GIS, the abundance of An. arabiensis within an endemic village in Yemen showed that the presence of televisions brings villagers together, thus rendering houses with televisions more attractive to An. arabiensis. Most of the houses with televisions had unprotected windows, and although windows were well fitted, nylon screens, if present, were usually badly torn, permitting mosquito entry. Such screens would achieve little anyway, since most houses leave the doors open for ventilation when rooms are crowded with people watching television. 
Although nocturnal biting cycles were not investigated in this study, and further research is needed to identify the circadian biting peaks of An. arabiensis and An. sergentii, the results provide useful information for making informed decisions about vector and malaria control in the region. For example, the practice of watching television throughout the first half of the night, and the exophilic behaviour of An. sergentii, present a challenge. Insecticide-treated bednets (ITNs) would not be effective in households with televisions and alternatives would have to be considered. Entering mosquitoes might be reduced with insecticide-treated curtains (ITCs), which have been shown to reduce malaria transmission in Burkina Faso [91, 92]. Impregnated curtains could be fitted on windows and doors and could possibly prevent mosquitoes from entering these houses while the owners and neighbours watch television. Most of the windows and doors are small; therefore, it is feasible to fit insecticide-treated curtains. Indeed, although these social activities take place at night, they expose humans to anopheline mosquito bites much as diurnal activities expose people to the bites of Aedes aegypti in and around homes. Given that ITCs hung in homes have been shown to impact $A$. aegypti [93, 94], the possibility that similar interventions might be successful should be considered. However, no curtains were seen in the villages, where they would undoubtedly be considered a luxury item, unless the health benefits were to be promoted. With numerous small rooms and large families, villagers might accept these curtains more readily than ITNs, although ITNs would be suitable for houses without televisions, those with fewer family members and those where residents sleep outdoors during the hot weather. However, the introduction of ITNs and thus ITCs, as shown by the KAP survey, would probably be more acceptable in Ukaysh where the mosquito problem exists throughout the year, and perhaps less so in $\mathrm{Al}-$ Sa'dah where mosquitoes appear only following the rainy season. Not surprisingly, the respondents of the KAP survey conducted in Ukaysh stated they were more willing to use and pay for a bednet than those at Al-Sa'dah.

Both ITNs and ITCs would be expected to impact also on the exophilic An. sergentii. However, given the high proportion An sergentii females that had fed on cattle (67.3\%), treatment of cattle with pyrethroids, which has been shown to be effective against An. arabiensis $[95,96]$ and for reducing malaria transmission [97], might be considered.

Indoor residual spraying, while effective against endophilic mosquitoes such as An. arabiensis, would not impact on the exophilic An. sergentii. Moreover, most houses have mud inner surfaces, which may absorb insecticide and shorten the duration of its effectiveness. Indeed, some types of mud may break insecticides down chemically [98], further limiting the potential of this approach.
Most importantly, it is advisable to promote health education advice regarding malaria diagnosis, treatment, prevention and control, information on mosquito behaviour and the methods of control that will be applied eventually in Yemen, as part of the ventures jointly launched by the United Nations Environmental Programme, the Global Environment Facility and the WHO-Eastern Mediterranean Region [99], to ensure optimization of community acceptance and compliance, essential pre-requisites for successful malaria control.

\section{Additional file}

Additional file 1. House survey and knowledge, attitudes and perception (KAP) survey.

\section{Authors' contributions}

PJM, SAE and GB conceived the study. SAE carried out all fieldwork, laboratory procedures and analyses under supervision of PJM, GB and AA. Morphological identification of mosquitoes was confirmed by REH and molecular ID was performed by REH and AGB. SAE and LKH carried out climate and spatial analyses. SAE wrote the paper with contributions by all authors. All authors read and approved the final manuscript.

\section{Author details}

${ }^{1}$ Department of Vector Biology, Liverpool School of Tropical Medicine, Pembroke Place, Liverpool, UK. ${ }^{2}$ Department of Medical Parasitology, Faculty of Medicine and Health Sciences, University of Yemen, Sana'a, Yemen. ${ }^{3}$ Department of Parasitology, Liverpool School of Tropical Medicine, Pembroke Place, Liverpool, UK. ${ }^{4}$ Department of Life Sciences, Natural History Museum, Cromwell Road, London, UK.

\section{Acknowledgements}

We would like to thank the villagers for their cooperation during the entire period of study, to Dr. Abdullah Al Taiar (Department of Community Medicine and Behavioural Sciences, Faculty of Medicine, Kuwait University, Kuwait) for his support and to the National Malaria Control Programme (NMCP) of the Ministry of Health and Population) in the Republic of Yemen for assistance with fieldwork. We would like to also thank WHO/TDR and Sana'a University for funding this study. Finally, we are grateful to Shelley Cook and Lorna Culverwell for processing specimens for DNA sequencing during their time at the Natural History Museum, London.

\section{Competing interests}

The authors declare that they have no competing interests.

Received: 13 January 2016 Accepted: 17 February 2016

Published online: 01 March 2016

\section{References}

1. WHO. World Malaria Report 2013. Geneva: World Health Organization; 2013. [http://www.who.int/malaria/publications/world_malaria_ report 2013/en/]. Accessed 7 Jul 2014.

2. Snow RW, Amratia P, Zamani G, Mundia CW, Noor AM, Memish ZA, et al. The malaria transition on the Arabian Peninsula: progress toward a malaria-free region between 1960-2010. Adv Parasitol. 2013;82:205-51.

3. Abdulsalam MQA, Mohammed AKM, Ahmed AA, Fong MY. Clinical situation of endemic malaria in Yemen. Trop Biomed. 2010;27:551-8.

4. Al-Mekhlafi AM, Mahdy MA, Azazy AA, Fong MY. Molecular epidemiology of Plasmodium species prevalent in Yemen based on $18 \mathrm{~s}$ rRNA. Parasit Vectors. 2010;3:110. 
5. NMCP. Yemen's National Malaria Control and Elimination Strategic Plan (2011-2015). Sana'a: National Malaria Control Programme, Ministry of Health and Population. Republic of Yemen. 2010.

6. Al-Taiar A, Jaffar S, Assabri A, Al-Habori M, Azazy A, Al-Mahdi N, et al. Severe malaria in children in Yemen: two site observational study. BMJ. 2006;333:827.

7. NMCP. Towards a malaria-free Yemen. The National Strategy for Malaria Control and Elimination 2014-2018. National Malaria Control Programme, Ministry of Public Health and Population. Republic of Yemen. 2014.

8. Al-Taiar A, Assabri A, Al-Habori M, Azazy A, Algabri A, Alganadi M, et al. Socioeconomic and environmental factors important for acquiring non-severe malaria in children in Yemen: a case-control study. Trans R Soc Trop Med Hyg. 2009;103:72-8.

9. Al-Hamidhi S, Mahdy MA, Idris MA, Bin Dajem SM, Al-Sheikh AA, AlQahtani A, et al. The prospect of malaria elimination in the Arabian Peninsula: a population genetic approach. Infect Genet Evol. 2014;27:25-31.

10. NMCP. Annual Report. National Malaria Control Programme, Ministry of Public Health and Population. Republic of Yemen. 2002.

11. Kouznetsov RL. Distribution of anophelines in the Yemen Arab Republic and its relation to malaria. WHO/MAL/76.879. Geneva: World Health Organization; 1976: 1-9

12. Mount RA. Medical mission to the Yemen, Southwest Arabia, 1951. I. Geomedical observations. Am J Trop Med Hyg. 1953;2:1-12.

13. Al-Maktari MT, Bassiouny HK. Bionomics of anopheline vectors in Zabid District, Al-Hodeidah Governorate, Republic of Yemen. East Mediterr Health J. 1999;5:698-705.

14. Al-Sheikh AAH. Studies on the ecology, vectorial role and population structure of Anopheles arabiensis in the Tihama region of Saudi Arabia and Yemen. PhD, University of Liverpool. 2004.

15. WHO. Country Profiles. Yemen: World Health Organization, Regional office for the Eastern Mediterranean countries; 2005.

16. Buxton PA. Anopheles mosquitoes and malaria in Arabia. Trans R Soc Trop Med Hyg. 1944;38:205-14

17. Knight KL. The mosquitoes of the Yemen. Proc Ent Soc Wash. 1953;55:212-34

18. Merucci L. Several species of Anopheles found in various regions of Yemen (southwest Arabia). Nuovi Ann lg Microbiol. 1954;5:440-4.

19. Mattingly PF, Knight KL. The mosquitoes of Arabia. I. Bull Br Mus (Nat Hist) Entomol. 1956:4:91-141.

20. Maffi M. On some larvae of the Myzomyia series collected in the Yemen. Parassitologia. 1971;13:449-54

21. Kouznetsov RL. Discovery of Anopheles coustani Laveran, 1900 and Anopheles squamosus Theobald, 1901, on the territory of the Yemen Arab Republic. Med Parasit. 1971:4:441-3.

22. Daoud W. [Epidemiologic study of malaria in the foothill area of the Taez region of the Arabic Republic of Yemen](in French). Bull Soc Pathol Exot. 1988:81:351-9.

23. Ahmed NU. Distribution of Anopheles Meigen (Diptera: Culicidae) in the Governorate of Taiz of the Foothills and the Middle Heights Region. Yemen: NMCP; 1986

24. Suleman M. Assignment report on Entomological Situation Related to Epidemiology of Malaria in Yemen. 17 February-15 March 1999. NMCP Yemen, 1999.

25. Alkadi HO, Al-Maktari MT, Nooman MA. Chloroquine-resistant Plasmodium falciparum local strain in Taiz Governorate, Republic of Yemen. Chemotherapy. 2006;52:166-70.

26. Al-Taiar A, Jaffar S, Assabri A, Al-Habori M, Azazy A, Al-Gabri A, et al. Who develops severe malaria? Impact of access to healthcare, socio-economic and environmental factors on children in Yemen: a case-control study. Trop Med Int Health. 2008;13:762-70.

27. WHO. Manual on Practical Entomology in Malaria. Part II: Methods and techniques. Geneva: World Health Organization; 1975.

28. Service MW. Mosquito ecology: Field sampling methods. Elsevier Applied Science. 2nd ed. London. 1993.

29. Costantini C, Sagnon N, Sanogo E, Merzagora L, Coluzzi M. Relationship to human biting collections and influence of light and bednet in CDC light-trap catches of West African malaria vectors. Bull Entomol Res. 1998:88:503-11.

30. Glick J.. Illustrated Key to the Female Anopheles of Southwestern Asia and Egypt (Diptera: Culicidae). Mosq Syst. 1992;24:125-53.
31. Collins FH, Mendez MA, Rasmussen MO, Mehaffey PC, Besansky NJ, Finnerty $\mathrm{V}$. A ribosomal RNA gene probe differentiates member species of the Anopheles gambiae complex. Am J Trop Med Hyg. 1987;37:37-41.

32. Scott JA, Brogdon WG, Collins FH. Identification of single specimens of the Anopheles gambiae complex by the polymerase chain reaction. Am J Trop Med Hyg. 1993;49:520-9.

33. Mzilahowa T, Hastings IM, Molyneux ME, McCall PJ. Entomological indices of malaria transmission in Chikhwawa district, Southern Malawi. Malar J. 2012;11:380.

34. Gillies MT, de Meillon B. The Anophelinae of Africa south of the Sahara (Ethiopian Zoogeographical Region). Johannesburg: S Afric Inst Med Res; 1968

35. Gillies MT, Coetzee M. A supplement to the Anophelinae of Africa south of the Sahara (Afrotropical Region). Johannesburg: S Afric Inst Med Res; 1987.

36. Cook S, Bennett SN, Holmes EC, De Chesse R, Moureau G, de Lamballerie $X$. Isolation of a new strain of the flavivirus cell fusing agent virus in a natural mosquito population from Puerto Rico. J Gen Virol. 2006:87:735-48.

37. Beier JC, Perkins PV, Wirtz RA, Koros J, Diggs D, Gargan TP 2nd, et al. Bloodmeal identification by direct enzyme-linked immunosorbent assay (ELISA), tested on Anopheles (Diptera: Culicidae) in Kenya. J Med Entomol. 1988;25:9-16.

38. Wirtz RA, Avery M, Benedict M, Sutcliffe A. Plasmodium sporozoite ELISA. 2010. In: Methods in Anopheles Research, 2nd ed. Chapter 8.2. MR4, CDC.

39. Wirtz RA, Burkot TR, Andre RG, Rosenberg R, Collins WE, Roberts DR. Identification of Plasmodium vivax sporozoites in mosquitoes using an enzyme-linked immunosorbent assay. Am J Trop Med Hyg. 1985:34:1048-54.

40. International Research Institute for Climate and Society IRI/LDEO Climate Data Library. http://iridl.Ideo.columbia.edu/. Accessed 12 Feb 2016.

41. National Snow and Ice Data Center [http://nsidc.org/arcticmet/factors/ humidity.html] Accessed 12 Feb 2016.

42. Barnish G, Maude GH, Bockarie MJ, Eggelte TA, Greenwood BM, Ceesay S. Malaria in a rural area of Sierra Leone. I. Initial results. Ann Trop Med Parasitol. 1993;87:125-36.

43. Kirkwood BR. Transformations. In: Essentials of Medical Statistics. Oxford: Blackwell Scientific publications Ltd. 1998. p.138-146.

44. Altschul SF, Gish W, Miller W, Myers EW, Lipman DJ. Basic local alignment search tool. J Mol Biol. 1990;215:403-10.

45. Shililu JI, Maier WA, Seitz HM, Orago AS. Seasonal density, sporozoite rates and entomological inoculation rates of Anopheles gambiae and Anopheles funestus in a high-altitude sugarcane growing zone in Western Kenya. Trop Med Int Health. 1998;3:706-10.

46. Townson H, Harbach RE, Callan TA. DNA identification of museum specimens of the Anopheles gambiae complex: an evaluation of PCR as a tool for resolving the formal taxonomy of sibling spcies complex. Syst Entomol. 1999;24:95-100.

47. Faye O, Konate L, Mouchet J, Fontenille D, Sy N, Hebrard G, et al. Indoor resting by outdoor biting females of Anopheles gambiae complex (Diptera:Culicidae) in the Sahel of northern Senegal. J Med Entomol. 1997;34:285-9.

48. Hamad AA, Nugud AH, Arnot DE, Giha HA, Abdel-Muhsin AM, Satti GM, et al. A marked seasonality of malaria transmission in two rural sites in eastern Sudan. Acta Trop. 2002:83:71-82.

49. Mzilahowa T. Malaria transmission intensity and the population structure of Plasmodium falciparum in the lower Shire Valley, southern Malawi. PhD, University of Liverpool. 2005

50. Fornadel CM, Norris DE. Increased endophily by the malaria vector Anopheles arabiensis in Southern Zambia and identification of digested blood meals. Am J Trop Med Hyg. 2008;79:876-80.

51. White GB, Magayuka SA, Boreham PF. Comparative studies on sibling species of the Anopheles gambiae Giles complex (Dipt., Culicidae): bionomics and vectorial activity of species A and species B at the Segera, Tanzania. Bull Entomol Res. 1972;62:295-317.

52. Githeko AK, Service MW, Mbogo CM, Atieli FK, Juma FO. Plasmodium falciparum sporozoite and entomological inoculation rates at the Ahero rice irrigation scheme and the Miwani sugar-belt in western Kenya. Ann Trop Med Parasitol. 1993;87:379-91.

53. Mahande A, Mosha F, Mahande J, Kweka E. Feeding and resting behaviour of malaria vector, Anopheles arabiensis with reference to zooprophylaxis. Malar J. 2007;6:100 
54. Ralisoa Randrianasolo BO, Coluzzi M. Genetical investigations on zoophilic and exophilic Anopheles arabiensis from Antananarivo area (Madagascar). Parassitologia. 1987;29:93-7.

55. Sharp BL, Le Sueur DL. Behavioural variation of Anopheles arabiensis (Diptera: Culicidae) populations in Natal, South Africa. Bull Entomol Res. 1991;81:107-10.

56. Kulkarni MA, Kweka E, Nyale E, Lyatuu E, Mosha FW, Chandramohan D, et al. Entomological evaluation of malaria vectors at different altitudes in Hai district, northeastern Tanzania. J Med Entomol. 2006;43:580-8.

57. White GB. Anopheles gambiae complex and disease transmission in Africa. Trans R Soc Trop Med Hyg. 1974;68:278-301.

58. Githeko AK, Service MW, Mbogo CM, Atieli FK, Juma FO. Origin of blood meals in indoor and outdoor resting malaria vectors in western Kenya. Acta Trop. 1994;58:307-16.

59. Githeko AK, Adungo NI, Karanja DM, Hawley WA, Vulule JM, Seroney K, et al. Some observations on the biting behavior of Anopheles gambiae s.S., Anopheles arabiensis, and Anopheles funestus and their implications for malaria control. Exp Parasitol. 1996;82:306-15.

60. Tirados I, Costantini C, Gibson G, Torr SJ. Blood-feeding behaviour of the malarial mosquito Anopheles arabiensis: implications for vector control. Med Vet Entomol. 2006;20:425-37

61. Haridi AM. Partial Exophily of Anopheles gambiae species B in Khashm Elgirba Medto Area in Eastern Sudan. World Health Organization, WHO/ MAL/71.746. 1971.

62. Aboud MA. Ecology and population structure of Anopheles arabiensis in Sudan. PhD, University of Liverpool. 2003.

63. Krafsur ES. Malaria transmission in Gambela, Illubabor province. Ethiop Med J. 1971;9:75.

64. Thompson R, Begtrup K, Cuamba N, Dgedge M, Mendis C, GamageMendis A, et al. The Matola malaria project: a temporal and spatial study of malaria transmission and disease in a suburban area of Maputo, Mozambique. Am J Trop Med Hyg. 1997;57:550-9.

65. Kent RJ, Thuma PE, Mharakurwa S, Norris DE. Seasonality, blood feeding behavior, and transmission of Plasmodium falciparum by Anopheles arabiensis after an extended drought in southern Zambia. Am J Trop Med Hyg. 2007;76:267-74

66. Mwangangi JM, Mbogo CM, Nzovu JG, Githure JI, Yan G, Beier JC. Bloodmeal analysis for anopheline mosquitoes sampled along the Kenyan coast. J Am Mosq Control Assoc. 2003;19:371-5.

67. Kenawy MA, Beier JC, Asiago CM, el Said S. Factors affecting the humanfeeding behavior of anopheline mosquitoes in Egyptian oases. J Am Mosq Control Assoc. 1990;6:446-51.

68. Mukiama TK, Mwangi RW. Field studies of larval Anopheles arabiensis Patton of MWEA irrigation scheme. Kenya. Insect Sci Applic. 1989;10:55-62.

69. Farid MA. The implications of Anopheles sergenti for malaria eradication programmes east of the Mediterranean. Bull World Health Org. 1956;15:821-8.

70. Zaim M, Ershadi MR, Manouchehri AV, Hamdi MR. The use of CDC light traps and other procedures for sampling malaria vectors in southern Iran. J Am Mosq Control Assoc. 1986;2:511-5.

71. Salternik Z. The Specific Biological Characteristics of Anopheles (Myzomyia) sergentii (Theo.) and their correlation with malaria control in Israel. Bull Entomol Res. 1955:46:445-63.

72. Faraj C, Adlaoui E, Ouahabi S, Rhajaoui M, Fontenille D, Lyagoubi M. Entomological investigations in the region of the last malaria focus in Morocco. Acta Trop. 2009;109:70-3.

73. Harbach RE, Knight KL. Taxonomists' glossary of mosquito anatomy. New Jersey: Plexus Publishing Inc; 1980.

74. Taye A, Hadis M, Adugna N, Tilahun D, Wirtz RA. Biting behavior and Plas modium infection rates of Anopheles arabiensis from Sille, Ethiopia. Acta Trop. 2006;97:50-4.

75. Abdalla H, Matambo TS, Koekemoer LL, Mnzava AP, Hunt RH, Coetzee $M$. Insecticide susceptibility and vector status of natural populations of Anopheles arabiensis from Sudan. Trans R Soc Trop Med Hyg. 2008;102:263-71.

76. Temu EA, Minjas JN, Coetzee M, Hunt RH, Shift CJ. The role of four anopheline species (Diptera: Culicidae) in malaria transmission in coasta Tanzania. Trans R Soc Trop Med Hyg. 1998;92:152-8.

77. Shililu J, Ghebremeskel T, Seulu F, Mengistu S, Fekadu H, Zerom M, et al. Seasonal abundance, vector behavior, and malaria parasite transmission in Eritrea. J Am Mosq Control Assoc. 2004;20:155-64.
78. Drakeley C, Schellenberg D, Kihonda J, Sousa CA, Arez AP, Lopes D, et al. An estimation of the entomological inoculation rate for Ifakara: a semiurban area in a region of intense malaria transmission in Tanzania. Trop Med Int Health. 2003;8:767-74.

79. Taylor KA, Koros JK, Nduati J, Copeland RS, Collins FH, Brandling-Bennett AD. Plasmodium falciparum infection rates in Anopheles gambiae, An. arabiensis, and An. funestus in western Kenya. Am J Trop Med Hyg. 1990;43:124-9.

80. Wilson MD, Ofosu-Okyere A, Okoli AU, McCall PJ, Snounou G. Direct comparison of microscopy and polymerase chain reaction for the detection of Plasmodium sporozoites in salivary glands of mosquitoes. Trans R Soc Trop Med Hyg. 1998;92:482-3.

81. Abdoon AM, Alshahrani AM. Prevalence and distribution of anopheline mosquitoes in malaria endemic areas of Asir region, Saudi Arabia. East Mediterr Health J. 2003;9:240-7.

82. Shehata MG, Kenawy MA, el Said SM, Beier JC, Gwadz R, Shaaban M. Anopheles sergenti (Theobald) a potential malaria vector in Egypt. Ann Parasitol Hum Comp. 1989:64:72-6.

83. Kenawy MA, Beier JC, Asiago CM, el Said SE, Roberts CR. Interpretation of low-level Plasmodium infection rates determined by ELISA for anophelines (Diptera: Culicidae) from Egyptian oases. J Med Entomol. 1990;27:681-5.

84. Ashe P, O'Connor JP, Casey RJ. Irish mosquitoes (Diptera: Culicidae): a checklist of the species and their known distribution. Proc Royal Irish Acad. 1991;91:21-36.

85. Macdonald WW. Anophelines of Libya and their control. Gariounis Med J. 1982:5:72-4.

86. Conlon J. Vectors and War-'Desert Storm'. http://entomology.montana. edu/historybug/DStorm-Conlon.pdf. 1991. Accessed 12 Feb 2016.

87. Hay SI, Rogers DJ, Toomer JF, Snow RW. Annual Plasmodium falciparum entomological inoculation rates (EIR) across Africa: literature survey, Internet access and review. Trans R Soc Trop Med Hyg. 2000;94:113-27.

88. Thomson MC, D'Alessandro U, Bennett S, Connor SJ, Langerock P, Jawara $M$, et al. Malaria prevalence is inversely related to vector density in The Gambia, West Africa. Trans R Soc Trop Med Hyg. 1994;88:638-43.

89. Shililu J, Ghebremeskel T, Mengistu S, Fekadu H, Zerom M, Mbogo C, et al. High seasonal variation in entomologic inoculation rates in Eritrea, a semi-arid region of unstable malaria in Africa. Am J Trop Med Hyg. 2003;69:607-13.

90. Kelly-Hope LA, McKenzie FE. The multiplicity of malaria transmission: a review of entomological inoculation rate measurements and methods across sub-Saharan Africa. Malar J. 2009;8:19.

91. Cuzin-Ouattara N, Van den Broek AH, Habluetzel A, Diabate A, SanogoIlboudo E, Diallo DA, et al. Wide-scale installation of insecticide-treated curtains confers high levels of protection against malaria transmission in a hyperendemic area of Burkina Faso. Trans R Soc Trop Med Hyg. 1999:93:473-9.

92. Habluetzel A, Cuzin N, Diallo DA, Nebie I, Belem S, Cousens SN, et al. Insecticide-treated curtains reduce the prevalence and intensity of malaria infection in Burkina Faso. Trop Med Int Health. 1999;4:557-64.

93. Kroeger A, Lenhart A, Ochoa M, Villegas E, Levy M, Alexander N, et al. Effective control of dengue vectors with curtains and water container covers treated with insecticide in Mexico and Venezuela: cluster randomised trials. BMJ. 2006;332:1247-52.

94. Lenhart A, Orelus N, Maskill R, Alexander N, Streit T, McCall PJ. Insecticidetreated bednets to control dengue vectors: preliminary evidence from a controlled trial in Haiti. Trop Med Int Health. 2008;13:56-67.

95. Hewitt S, Rowland M. Control of zoophilic malaria vectors by applying pyrethroid insecticides to cattle. Trop Med Int Health. 1999;4:481-6.

96. Mahande AM, Mosha FW, Mahande JM, Kweka EJ. Role of cattle treated with deltamethrin in areas with a high population of Anopheles arabiensis in Moshi, Northern Tanzania. Malar J. 2007;6:109.

97. Rowland M, Durrani N, Kenward M, Mohammed N, Urahman H, Hewitt S. Control of malaria in Pakistan by applying deltamethrin insecticide to cattle: a community-randomised trial. Lancet. 2001;357:1837-41.

98. Rozendaal JA. Vector control: methods for use by individuals and communities. Geneva: World Health Organization; 1997.

99. Demonstration of sustainable alternatives to DDT and strengthening national vector control capabilities in the Middle East and North Africa. Malaria Control and Elimination. [http://www.emro.who.int/malaria/gefprojects/gef-project.html]. Accessed 12 Feb 2016. 